\title{
Artificial Neural Network (ANN) Approach to Predict an Optimized pH-Dependent Mesalamine Matrix Tablet
}

This article was published in the following Dove Press journal: Drug Design, Development and Therapy

\author{
Asad Majeed Khan ${ }^{1,2}$ \\ Muhammad Hanif' \\ Nadeem Irfan Bukhari (iD) ${ }^{3}$ \\ Rahat Shamim (D) ${ }^{3}$ \\ Fatima Rasool ${ }^{3}$ \\ Sumaira Rasul ${ }^{4}$ \\ Sana Shafique ${ }^{5}$ \\ 'Faculty of Pharmacy, Bahauddin Zakriya \\ University, Multan, Pakistan; ${ }^{2}$ Lahore \\ Pharmacy College, Lahore Medical and \\ Dental College, Lahore, Pakistan; \\ ${ }^{3}$ University College of Pharmacy, \\ University of the Punjab, Lahore, \\ Pakistan; ${ }^{4}$ Institute of Molecular Biology \\ and Biotechnology, Bahauddin Zakriya \\ University, Multan, Pakistan; ${ }^{5}$ Faculty of \\ Pharmacy, Rippha International \\ University, Lahore, Pakistan
}

\section{Video abstract}

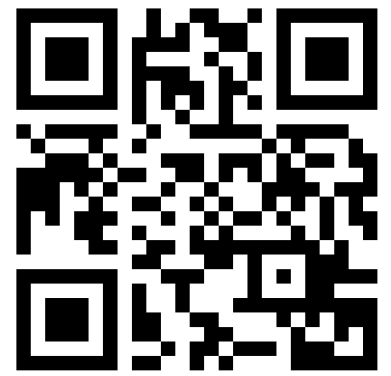

Point your SmartPhone at the code above. If you have a $Q R$ code reader the video abstract will appear. Or use: https://youtu.be/AP32Khl 62pU

Correspondence: Muhammad Hanif; Nadeem Irfan Bukhari

Email Muhammad.hanif@bzu.edu.pk; nadeem_irfan@hotmail.com
Background: Severe bleeding and perforation of the colon and rectum are complications of ulcerative colitis which can be treated by a targeted drug delivery system.

Purpose: Development of colon-targeted delivery usually involves a complex formulation process and coating steps of $\mathrm{pH}$-sensitive methacrylic acid based Eudragit ${ }^{\circledR}$. The current work was purposefully designed to develop dicalcium phosphate (DCP) facilitated with Eudragit-S100-based pH-dependent, uncoated mesalamine matrix tablets.

Materials and Methods: Mesalamine formulations were compressed using wet granulation technique with varying compositions of dicalcium phosphate (DCP) and Eudragit-S100. The developed formulations were characterized for physicochemical and drug release profiles. Infrared studies were carried out to ensure that there was no interaction between active ingredients and excipients. Artificial neural network (ANN) was used for the optimization of final DCP-Eudragit-S100 complex and the experimental data were employed to train a multilayer perception (MLP) using quick propagation (QP) training algorithm until a satisfactory root mean square error (RMSE) was reached. The ANN-aided optimized formulation was compared with commercially available Masacol ${ }^{\circledR}$.

Results: Compressed tablets met the desirability criteria in terms of thickness, hardness, weight variation, friability, and content uniformity, ie, $5.34 \mathrm{~mm}, 7.7 \mathrm{~kg} / \mathrm{cm}^{2}, 585 \pm 5 \mathrm{mg}(\%)$, $0.44 \%$, and $103 \%$, respectively. In-vitro dissolution study of commercially available mesalamine and optimized formulation was carried out and the former showed $100 \%$ release at 6 $\mathrm{h}$ while the latter released only $12.09 \%$ after $2 \mathrm{~h}$ and $72.96 \%$ after $12 \mathrm{~h}$ which was fitted to Weibull release model with $b$ value of 1.3 , indicating a complex release mechanism.

Conclusion: DCP-Eudragit-S100 blend was found explicative for mesalamine release without coating in gastric and colonic regions. This combination may provide a better control of ulcerative colitis.

Keywords: ulcerative colitis, DCP-Eudragit-S100 complex, phosphatidylserine, Weibull release model

\section{Introduction}

Ulcerative colitis (UC) is a chronic inflammatory condition characterized by deregulated immune response of intestinal microflora which ultimately limits the mucosal layer of the colon and rectum and is known for its remission and relapse throughout life. ${ }^{1,2}$ Untreated ulcerative colitis may cause severe bleeding, hole in the colon (perforated colon), severe dehydration, and increased risk of colon cancer. Oral treatment in UC treatment is preferred as compared to suppositories due to its ease of manufacturing, storing conditions, and patient compliance. 5-aminosalicylic 
acid (5-ASA), an anti-inflammatory agent has gained the status of drug of first choice in the treatment of active mild to moderate UC. ${ }^{3}$ Among many advantages of oral dosage, dissolution and absorption of drugs in the small intestine reduces its concentration in the colon which results in failure of minimum effective concentration (MEC) of drugs. $^{4}$

UC can be treated successfully by targeted localized drug delivery to the colon, avoiding systemic concentration. It has been established that therapeutic effect of mesalamine is concentration-dependent, which led to the development of dosage forms which deliver the drug directly to the inflamed tissue with relatively low side effects. ${ }^{5}$ For the past two decades, delayed release mesalamine has been used for treating UC. ${ }^{6}$ But colon-targeted drug delivery systems involve difficult preparation procedures and certain management, thereby making the system complex and expensive. Different strategies like pro-drug, enteric coating and $\mathrm{pH} /$ time-dependent modified release, microfloraactivated system, pressure controlled drug delivery system (PCDCS), osmotic controlled drug delivery to colon (OROS-CT), and pulsatile drug delivery have gained attention. ${ }^{7}$ Based upon these strategies, the different products of 5-aminosalicylic acid (5-ASA) available are Pentasa $^{\circledR}$ MR coated timed release microgranules, Asacol $^{\circledR}$ and Aspiro ${ }^{\circledR}$ CR double layered enteric coated tablets, Lialda ${ }^{\circledR}$ XL Multimatrix SR hydrophilic/lipophilic matrix core tablets, Octasa ${ }^{\circledR}$ MR pH sensitive coated tablets and Salofalk ${ }^{\circledR}$ gastric-resistant granules coated by $\mathrm{pH}-$ independent polymer. $^{8-13}$ But their polymer-dependent behavior and predicted drug release in the colon remained debatable. Besides taking large dose orally, prodrug has the disadvantage of linking moiety which may cause non-drug related side effects. In time-dependent systems, gastric emptying time and GI transit time limit predicted drug release in the colon. pH-dependent systems which involve enteric coating cannot be easily engineered due to interaction of enteric coated polymeric mixture with hydrophobic additives like magnesium stearate.

Therefore, a pH-dependent targeted drug delivery system was designed by simple wet granulation and without coating, with the advantages of minimum release of drug in upper GIT and enhanced local delivery of drug to the colon. ${ }^{14}$ Eudragit-S100 is used as a coating agent in delayed release formulations and preferred in colon-targeted delivery due to its sensitivity to alkaline $\mathrm{pH}$ of 7.2. Eudragit-S100 is an anionic copolymer based on methacrylic acid and methyl methacrylate with the ratio of 1:2. Use of Eudragit-S100 alone for delayed release is restricted due to its gel forming and diffusion behavior. Dual nature of di-calcium phosphate (DCP), ie, as a binder and release retardant, can facilitate the combination of Eudragit-S100. The resultant complex of Eudragit-S100 and DCP can create the delayed release characteristic not only in the colon but can also prevent the GIT degradation of drugs. ${ }^{14-16}$

Therefore, attempts were made to develop Eudragit-S100 and DCP complex in uncoated delayed release matrix tablets of 5-ASA. ${ }^{17}$ Two different types, un-milled and milled form, of DCP were used as diluent previously but presently only the latter was employed. ${ }^{16}$ Drug release was controlled by varying compositions of the ingredients. Computer-aided technique; Artificial Neural Network (ANN) was employed to catechize the effect of different compositions in twentythree formulations to optimize a delivery system with desired dissolution profile of mesalamine. ANN is an effective approach to estimate the quantity of the formulation ingredients which may meet the desirability criteria. ${ }^{18}$ In-vitro dissolution study was carried out to note the drug release up to $70 \%$ until $12 \mathrm{~h}$ which ensured a delayed release dosage form. The designed delayed release tablets of mesalamine will provide the required concentration of the drug at the site of inflammation to treat UC successfully.

\section{Materials and Methods}

Mesalamine was kindly gifted by Getz Pharma, Karachi. Eudragit-S100 was obtained from Highnoon Pharmaceuticals, Lahore. Dicalcium phosphate (DCP), polyvinyl-pyrrolidone-K30 (PVP-K30), magnesium stearate, isopropyl alcohol (IPA), potassium chloride, potassium monohydrogen phosphate, sodium hydroxide, and hydrochloric acid were all purchased from Sigma Aldrich, Germany, sodium starch glycolate (SSG) and ethyl cellulose (EC) were obtained from Merck ${ }^{\circledR}$ Darmstadt Germany. All the chemicals used in the study were of analytical grade.

Wet granulation technique was used for the compression of mesalamine tablets as described elsewhere. ${ }^{19}$ Briefly; compression was divided into five stages for the successful application of ANN. Stage 1 was mixing (Mix), stage 2 was granulation stage 1 (GS-1), stage 3 was granulation stage 2 (GS-2), stage 4 was final mixing (F-mix), and stage 5 was compaction. Total quantity of DCP used was divided into almost two equal parts, part $\mathrm{A}$ and $\mathrm{B}$. In mix stage, mesalamine, Eudragit-S100, and PVP-K30 were geometrically mixed with a mortar and pestle for $10 \mathrm{~min}$ followed by addition of approximately half of DCP of part A as slurry with IPA (termed as DCP internal 1) until uniform wet mass 
was obtained. Wet mass was passed through sieve\#16 followed by GS-1 which comprised only oven drying for a period of $4 \mathrm{~h}$ at $50^{\circ} \mathrm{C} .^{20}$ In GS-2, dried granules were mixed again with the remaining half of DCP part A (termed as DCP internal 2) and were passed through sieve\#22. The granules were dried in a tray drier (IMS corporation Lahore, Pakistan) at $50^{\circ} \mathrm{C}$ for $2 \mathrm{~h}^{21}$ In F-mix stage, these granules were mixed with part B of DCP as dry powder (termed as DCP external) and magnesium stearate. ${ }^{22}$ These granules were then compressed into tablets and were stored in controlled airtight containers and compared with Masacol ${ }^{\circledR}$ (mesalamine by Getz Pharma Karachi, Pakistan). The five stages of compression along with details of each step have been shown in Figure 1.

\section{Characterization of Matrix Tablets}

The prepared tablets were evaluated for their friability, thickness, hardness, weight variation, and drug content assay. Friability of twenty tablets was determined in Roche Friabilator (IMS Corporation, Lahore, Pakistan) for $4 \mathrm{~min}$ at $25 \mathrm{rpm}$. Thickness of tablets was measured by digital screw gauge (Galvano Scientific Ltd, Lahore, Pakistan) by taking 20 tablets from each combination. ${ }^{23}$ Hardness of ten tablets was measured using digital hardness tester (Erweka, Germany). Weight variation was determined by taking average weight of twenty tablets using digital weight measuring balance (Sartorius Germany). For drug content assessment, 10 tablets were crushed and the aliquot of powdered tablet equivalent to $400 \mathrm{mg}$ of drug was dissolved in $50 \mathrm{~mL}$ of phosphate buffer $\mathrm{pH}$ 7.2. The solution was filtered through $0.45 \mu \mathrm{m}$ membrane filter. Sample was precisely diluted and analyzed on UV-spectrophotometer at $234 \mathrm{~nm}$. Percentage of mesalamine present in solution was calculated from the standard calibration curve. ${ }^{24}$

\section{Drug Dissolution and Release Study}

USP dissolution II paddle apparatus (Vision ${ }^{\circledR}$, California) rotated at $100 \mathrm{rpm}$ was used for two stage mesalamine delayed release studies. ${ }^{4}$ Two different dissolution mediums, $0.2 \mathrm{M} \mathrm{HCl} \mathrm{pH} 1.2$ (simulation of stomach $\mathrm{pH}$ ) for 2 $\mathrm{h}$ and phosphate buffer $0.2 \mathrm{M}$ of $\mathrm{pH} 7.2$ (simulation of colon $\mathrm{pH}$ ) for further $6 \mathrm{~h}$ at $37 \pm 0.5^{\circ} \mathrm{C}$, were used. ${ }^{25-27}$ $5 \mathrm{~mL}$ aliquot was withdrawn which was replaced with fresh acidic medium for first $2 \mathrm{~h}$ and with basic phosphate buffer $\mathrm{pH} 7.2$ for remaining $6 \mathrm{~h} .{ }^{28}$ Collected samples were filtered through $0.45 \mu \mathrm{m}$ Millipore filters and mesalamine concentration was measured at $234 \mathrm{~nm}$ after appropriate dilutions of samples.

\section{Kinetics of Drug Release}

Release kinetic modeling was carried out using Microsoft Excel based adds in program DD Solver Ver 1.0. The kinetic models were applied by using the following equations: ${ }^{29}$

$$
\begin{gathered}
Q_{t}=K_{0} t \\
Q_{t}=\ln Q_{0}-K_{1} t \\
Q_{H}=K_{H} \sqrt{t}
\end{gathered}
$$

Where $\mathrm{Q}_{t}$ and $\mathrm{Q}_{\mathrm{H}}$ are the mean percentage of drug release, $\mathrm{t}$ is time in $\mathrm{h}, \mathrm{K}_{0}, \mathrm{~K}_{1} \mathrm{~K}_{\mathrm{H}}$ are zero, first and Higuchi order release constant expressed in concentration/time respectively.

$$
M_{t} / M_{\infty}=K_{t^{n}}
$$

Where $M_{t} / M_{\infty}$ is a fraction of drug released at time $\mathrm{t}, \mathrm{k}$ is the release rate constant and $\mathrm{n}$ is the release exponent.

In Peppas (Fickian diffusion) model, mechanisms of drug release are characterized using the release exponent ("n" value). An " $n$ " value of 1 corresponds to zero-order release kinetics (case II transport); $0.5<\mathrm{n}<1$ means an anomalous (non-Fickian) diffusion release model; $\mathrm{n}=0.5$ indicates Fickian diffusion, and $\mathrm{n}>1$ indicates a super case II transport relaxational release. ${ }^{30}$ The regression analysis data evaluate the kinetics of drug release from the prepared formulations. ${ }^{31}$

$$
\sqrt[3]{W_{0}}-\sqrt[3]{W_{t}}=\kappa t
$$

In Hixson-Crowell model, $W_{0}$ is the initial amount of drug in pharmaceutical dosage form, $W_{t}$ is the remaining amount of drug in pharmaceutical dosage form at time $t$ and $\mathrm{K}$ (kappa) is a constant incorporating the surfacevolume relation.

$$
\log [-\ln (1-m)]=b \log \left[t-T_{i}\right]-\log a
$$

In Weibull model, $a$ is the scale parameter which describes the time dependence, $b$ describes the shape of dissolution curve dependence and $m$ is the amount of drug dissolved. The model which showed the highest value of coefficient of determinants $\left(\mathrm{R}^{2}\right)$ and lowest value of Akaike information criterion (AIC) was categorized as best model that described the release. 


\section{ANN-Assisted Colonic Delivery System of Mesalamine}

ANN Neural Power ${ }^{\circledR}$ version 3.1 was used to study the relative effects of Eudragit-S100, DCP and PVP-K30 on hardness and in-vitro dissolution for $2-8 \mathrm{~h} .{ }^{32}$ Quick propagation (QP) method was employed for the data learning algorithm with Tanh as transfer function until a satisfactory root mean square error (RMSE), less than 1 was reached. ${ }^{33}$ Multilayer perception (MLP) structure was used in the study where the class of structure was feed forward. The total number of inputs, outputs and hidden layers was 5,8 , and 1, respectively, shown in Figure 1. Surface responses for the importance of excipients against hardness and in-vitro release were generated. ${ }^{34}$ For the prediction of the best levels of polymers to further retard the drug release until 12 $\mathrm{h}$ "What if" approach of ANN was used. On the basis of ANN predicted composition, F24 was compressed with some adjustments as shown in Table 1 to confirm the ANN prediction.

\section{Characterization of ANN Assisted Formulation}

The ANN assisted formulation was characterized in terms of friability, thickness, hardness, weight variation, dissolution and kinetics of release. Kinetics of drug release was studied by model independent approaches using already described DDSolver. The values of dissimilarity factor $f_{1}$ and similarity factor $f_{2}$ for F23 and F24 were calculated on the basis of release profile as reported in literature ${ }^{35}$ and compared with commercially available mesalamine, by using the following equations.

$$
\begin{gathered}
f_{1}=\left[\frac{\sum_{t=1}^{n}\left(R_{t}-T_{t}\right)}{\sum_{t=1}^{n} R_{t}}\right] \times 100 \\
f_{2}=50 \times \log \left[\left\{1+\left(\frac{1}{n}\right) \sum_{t=1}^{n}\left(R_{t}-T_{t}\right)^{2}\right\}^{-0.5} \times 100\right]
\end{gathered}
$$

where $n$ is the sample number, and $R_{t}$ and $T_{t}$ are the percentage of the reference and test drug release, respectively, at different time intervals.

\section{Fourier Transform Infrared Spectroscopy (FTIR)}

Infrared (IR) spectra for the pure drug, selected excipients and ANN assisted formulation were recorded on attenuated total reflectance (ATR) attached FTIR spectrophotometer

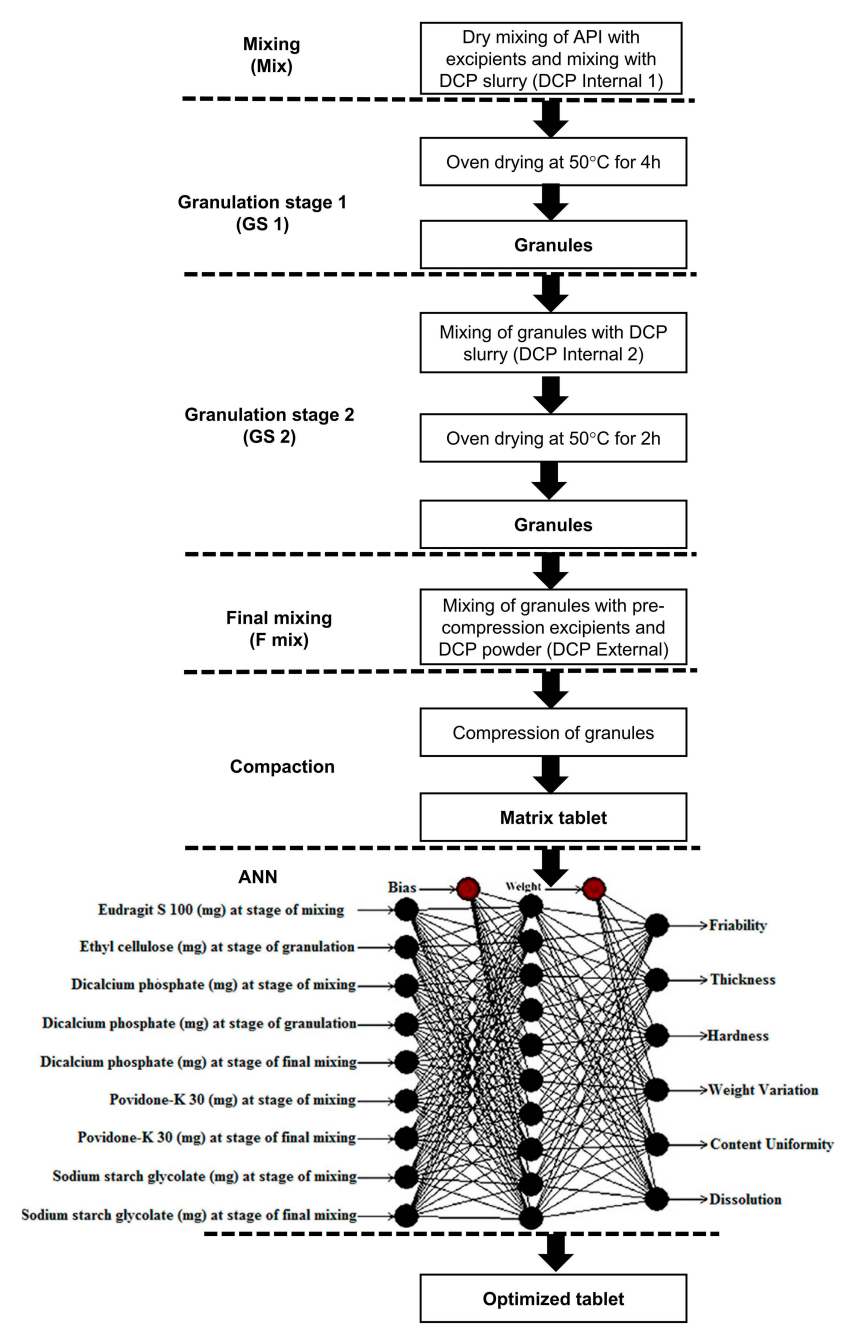

Figure I Scheme of study showing five stages of compression: Mix, GS-I, GS-2, F-mix and compression and structure of ANN applied using quick propagation method for data learning algorithm.

(FTIR-Agilent Technologies). Spectrum was taken from the wavelength of $500-4000 \mathrm{~cm}^{-1.36}$

\section{Results}

Different ratios of Eudragit-S100 and DCP were used successfully and 24 formulations were compressed by wet granulation method. Physicochemical properties of the powder blend and compressed tablets were within the limits (Table 2). Out of 24 formulations, F1 to F23 were prepared stepwise by controlling the composition of ingredients for desired outputs. The 24th formulation (F24) was prepared by the optimized levels of the ingredients predicted by ANN approach.

\section{In-vitro Drug Release}

In-vitro dissolution of prepared formulations was conducted in acidic medium for initial $2 \mathrm{~h}$ followed by 


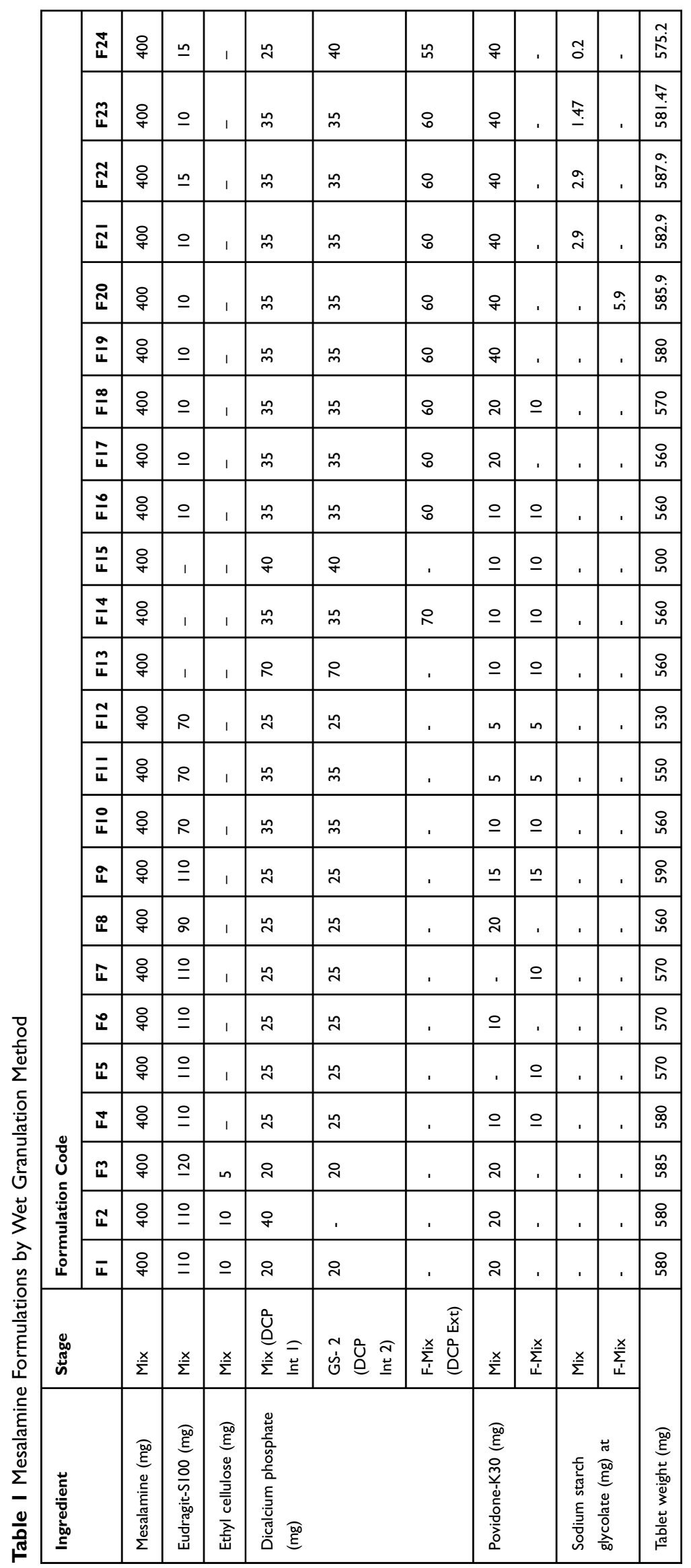


evaluation in basic medium for further $6 \mathrm{~h}$, except F23 which was studied for $12 \mathrm{~h}$ using the same tablets due to its $71.66 \%$ release within the first $8 \mathrm{~h}$. The graphical representation of drug release data of formulations F1F22 due to the effect of formulation variables is shown in Figures 2 and 3. Prepared formulations did not show an adequate release in acidic media during first $2 \mathrm{~h}$ of this study, therefore, the release data for $1 \mathrm{~h}$ had not been given in any graphical and tabular representation. It was observed that formulations F1-F3 containing varying concentrations of DCP, Eudragit-S100, and EC had shown less than 9\% drug release in $8 \mathrm{~h}$. This high drug retardation might be attributed to the $\mathrm{EC}$ due to its binding effect that increased tablet hardness. ${ }^{35}$ For this reason, EC was excluded from the next set of formulations F4-F12 which were prepared by varying concentrations of DCP and Eudragit-S100 in pre-decided ratio (Table 1). Non-desirable release pattern in F4 to F12 was observed throughout the study. The mesalamine release retardation might be attributed to the presence of Eudragit-S100. ${ }^{37}$ Another set of formulations were prepared by excluding Eudragit-S100 and using DCP as bulking agent in F13-F15 to maintain the desired tablet weight. The findings of release of drug from F13F15 demonstrated a breakthrough in the role of DCP, as release retardant. This set met the desirability of release criteria until $4 \mathrm{~h}$ but failed to exhibit required release until 8 h. For formulation F16 and onwards, EudragitS100 was included in combination with DCP which exaggerated a smooth drug release pattern to help obtain the desired sustained drug release characteristics which enabled the dosage form to target the colon without coating the dosage form. For the set of formulations F16-F19, PVP K30 was varied but desired release pattern was not achieved. It was noted that in this set of formulations, a small amount of Eudragit-S100 (2\%) in combination with DCP helped to control the initial 2 $\mathrm{h}$ release and DCP External for smooth delayed release in 3-8 h. In this combination, the required amount of Eudragit-S100 was less than which has been reported. ${ }^{37}$ Sodium starch glycolate was added as the superdisintegrant in F20-F23 to further enhance the smooth release pattern. Outcomes of all formulations were still not considered acceptable in terms of sustained drug delivery specifically from $2-5 \mathrm{~h}$ in small intestine, since drug release deviated from the desired profile.

Table 2 Physicochemical Characteristics of Mesalamine Formulations (Mean \pm S.D)

\begin{tabular}{|c|c|c|c|c|c|}
\hline Code & Friability (\%) & Thickness (mm) & Hardness $\left(\mathrm{kg} / \mathrm{cm}^{2}\right)$ & Weight Variation (mg) & Content Uniformity (\%) \\
\hline $\mathrm{FI}$ & $0.15 \pm 0.03$ & $4.05 \pm 0.02$ & $16.93 \pm 2.37$ & $591.4 \pm 3.95$ & $100.66 \pm 1.24$ \\
\hline F2 & $0.17 \pm 0.05$ & $4.23 \pm 0.01$ & $26.45 \pm 1.63$ & $587 \pm 3.87$ & $91.66 \pm 2.86$ \\
\hline F3 & $0.35 \pm 0.19$ & $4.3 \mathrm{I} \pm 0.0 \mathrm{I}$ & $25.16 \pm 1.86$ & $596.7 \pm 3.25$ & $95.33 \pm 2.86$ \\
\hline $\mathrm{F} 4$ & $0.32 \pm 0.11$ & $4.24 \pm 0.02$ & $23.53 \pm 4.77$ & $590.9 \pm 4.01$ & $90 \pm 2.44$ \\
\hline F5 & $0.17 \pm 0.07$ & $4.14 \pm 0.01$ & $22.86 \pm 1.97$ & $576.5 \pm 4.5$ & $92 \pm 2.44$ \\
\hline F6 & $0.25 \pm 0.11$ & $4.22 \pm 0.01$ & $|6.4| \pm 0.64$ & $584.5 \pm 2.29$ & $90 \pm 4.32$ \\
\hline F7 & $0.35 \pm 0.15$ & $4.55 \pm 0.05$ & $12.56 \pm 0.58$ & $576.1 \pm 3.7$ & $100.33 \pm 2.49$ \\
\hline F8 & $0.04 \pm 0.09$ & $5.15 \pm 0.02$ & $9.06 \pm 0.24$ & $574.4 \pm 4.54$ & $|02 \pm| .4 \mid$ \\
\hline F9 & $0.11 \pm 0.01$ & $5.24 \pm 0.03$ & $8.16 \pm 0.73$ & $603.8 \pm 4.37$ & $103.66 \pm 0.94$ \\
\hline FIO & $0.21 \pm 0.04$ & $5.18 \pm 0.02$ & $7.03 \pm 1.13$ & $574.1 \pm 4.3$ & $102.33 \pm 2.05$ \\
\hline FII & $0.25 \pm 0.09$ & $5.05 \pm 0.05$ & $7.25 \pm 1.15$ & $577.4 \pm 4.24$ & $97.33 \pm 1.69$ \\
\hline $\mathrm{FI} 2$ & $0.05 \pm 0.08$ & $5.23 \pm 0.01$ & $7.55 \pm 1.25$ & $577.5 \pm 4.08$ & $102.66 \pm 2.62$ \\
\hline $\mathrm{FI3}$ & $0.43 \pm 0.30$ & $4.56 \pm 0.05$ & $10.22 \pm 1.17$ & $574.8 \pm 4.21$ & $104.33 \pm 3.29$ \\
\hline $\mathrm{FI} 4$ & $0.21 \pm 0.26$ & $4.03 \pm 0.01$ & $12.63 \pm 0.75$ & $573.3 \pm 4.42$ & $106.66 \pm 1.24$ \\
\hline FI5 & $0.33 \pm 0.14$ & $4.13 \pm 0.01$ & $8.53 \pm 1.26$ & $573.2 \pm 4.53$ & $101.33 \pm 2.49$ \\
\hline FI6 & $0.33 \pm 0.15$ & $4.04 \pm 0.01$ & $9.13 \pm 0.33$ & $573.8 \pm 4.77$ & $100.66 \pm 1.69$ \\
\hline FI7 & $0.42 \pm 0.08$ & $4.04 \pm 0.02$ & $11.76 \pm 2.09$ & $578.3 \pm 3.9$ & $103.66 \pm 1.24$ \\
\hline FI8 & $0.20 \pm 0.05$ & $4.24 \pm 0.02$ & $12.46 \pm 0.37$ & $579.8 \pm 3.78$ & $99.33 \pm 1.24$ \\
\hline FI9 & $0.22 \pm 0.10$ & $4.24 \pm 0.02$ & $10.36 \pm 0.49$ & $579.4 \pm 4.38$ & $97.33 \pm 1.69$ \\
\hline $\mathrm{F} 20$ & $0.23 \pm 0.04$ & $5.33 \pm 0.01$ & $7.5 \pm 1.44$ & $588.8 \pm 4.06$ & $101.33 \pm 1.24$ \\
\hline F2I & $0.18 \pm 0.04$ & $5.05 \pm 0.02$ & $7.9 \pm 0.61$ & $589.7 \pm 3.31$ & $102.66 \pm 1.69$ \\
\hline F22 & $0.16 \pm 0.05$ & $5.43 \pm 0.01$ & $7.7 \pm 0.57$ & $587.2 \pm 4.11$ & $101.33 \pm 1.24$ \\
\hline F23 & $0.20 \pm 0.04$ & $5.35 \pm 0.02$ & $7.83 \pm 0.84$ & $584.4 \pm 4.24$ & $103.33 \pm 1.24$ \\
\hline
\end{tabular}




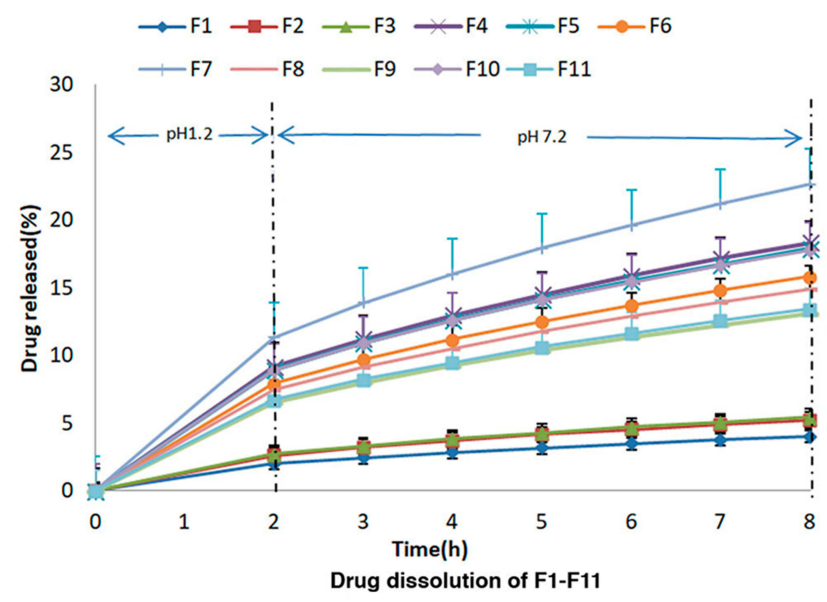

Figure 2 Percentage release studies of mesalamine from formulation FI-FII using $0.2 \mathrm{M} \mathrm{HCl}$ for $2 \mathrm{~h}$ at $\mathrm{pH} \mathrm{I} .2$ and $0.2 \mathrm{M}$ phosphate buffer at $\mathrm{pH} 7.2$ for further $6 \mathrm{~h}$.

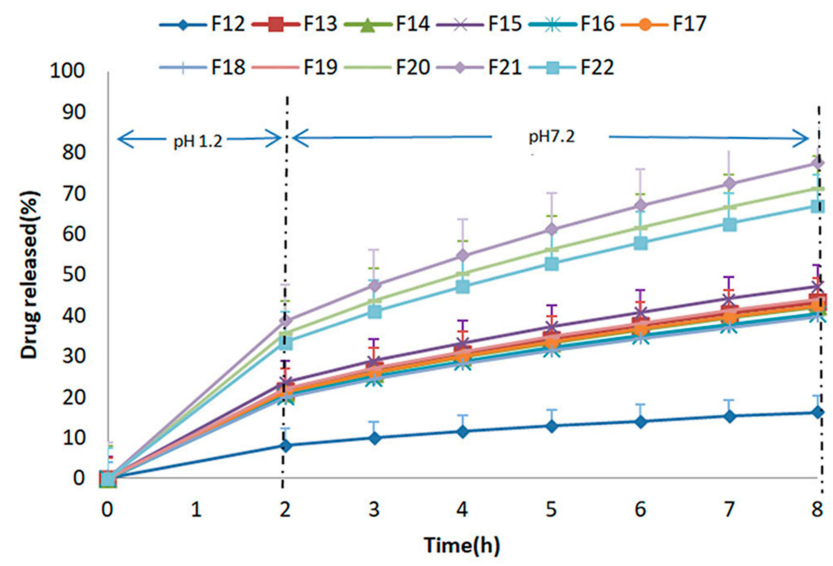

Figure 3 Percentage release studies of mesalamine from formulation FI2-F22 using $0.2 \mathrm{M} \mathrm{HCl}$ for $2 \mathrm{~h}$ at $\mathrm{pH} \mathrm{I} .2$ and $0.2 \mathrm{M}$ phosphate buffer at $\mathrm{pH} 7.2$ for further $6 \mathrm{~h}$.

\section{Release Kinetics and Mechanism}

The kinetic mechanisms for the drug release from all the formulations were plotted, and the coefficients of the drug release $\left(\mathrm{R}^{2}\right)$ were calculated as presented in Table 3. In the present study, most of the formulations exhibited $n$ value greater than 1, indicative of super case II transport release. $\mathrm{R}^{2}$ for Hixson Crowell cube root indicated uniform exhaustion of the drug delivery system. ${ }^{38}$ The drug release profiles with highest $\mathrm{R}^{2}$ and lowest AIC values among all kinetics models indicated that the release data for majority of the formulations were best fitted to Weibull model.

\section{ANN-Assisted Colon-Targeted Formulation}

Based on the inputs given, ANN foretold five sets of the compositions with their characteristics (outputs) predicted
(Table 4). Among these five sets, set 4 was selected for preparing optimized formulation (F24). The composition of this set was close to the composition of F23 which had shown best release (Figure 4) against the desirability criteria. ${ }^{35}$ F24 was prepared after minor adjustments to amounts such as $3 \mathrm{mg}$ of Eudragit-S100, $5 \mathrm{mg}$ of DCPInternal 2 and $20 \mathrm{mg}$ of DCP-External as mentioned (Table 1).

The adjustment in composition regarding DCPExternal was based on the maintenance of the tablet weight in accordance with the previous formulations, regardless of the final weight of the tablet formulations. The physicochemical and release profile for formulation F24 were measured. The release profile and characteristics of the colon-targeted formulation matched the predicted outputs given (Table 4).

\section{Characteristics of ANN Predicted Formulation}

The physicochemical characteristics of the ANN predicted mesalamine formulation (F24) showed friability $0.44 \%$, thickness $5.34 \mathrm{~mm}$, hardness $7.73 \mathrm{~kg} / \mathrm{cm}^{2}$, weight variation $585 \pm 3.42$ and drug content $103 \%$. The release kinetic analysis of all formulations and comparative release of F23 and F24 have been given in Table 3 and Figure 4 respectively.

\section{Comparative Release Profiles}

Desired released criteria for Colon-Targeted Drug Delivery System from delayed release matrix tablets have been cited in literature. ${ }^{35}$ In the present study, it was found that F23 was close to the desired release of $70 \%$ but this release occurred earlier in $8 \mathrm{~h}$. ANN predicted composition F24 produced further retardation in mesalamine release and clearly indicated a sustained smooth drug release from $0-12 \mathrm{~h}$. The drug release pattern of F23 and F24 along with desired release criteria have been illustrated in Figure 4.

In terms of release, dissimilarity $\left(f_{1}\right)$ and similarity $\left(f_{2}\right)$ data from DDSolver showed that formulation 24 was similar to that of the desired release profile of the delayed release formulations having $f_{1} \quad 10.14$ and $f_{2} 63.86$. Formulation F23 lost its closeness from the desired profile due to difference of release at time intervals of 3-7 h. F24 was also compared with mesalamine in terms of release and it showed $f_{1} 68.12$ and $f_{2} 23.32$ which proved to be different from the available market product. 
Table 3 Dissolution Kinetic Modeling of All Selected Formulations

\begin{tabular}{|c|c|c|c|c|c|c|c|c|c|c|c|c|c|}
\hline \multirow[t]{2}{*}{ Code } & \multicolumn{2}{|c|}{ Zero Order } & \multicolumn{2}{|c|}{ First Order } & \multicolumn{2}{|c|}{ Higuchi } & \multicolumn{2}{|c|}{ Hixon Crowell } & \multicolumn{2}{|c|}{ Weibull } & \multicolumn{3}{|c|}{ Korsmeyer-Peppas } \\
\hline & $\mathbf{R}^{2}$ & AIC & $\mathbf{R}^{2}$ & AIC & $\mathbf{R}^{2}$ & AIC & $\mathbf{R}^{2}$ & AIC & $\mathbf{R}^{2}$ & AIC & $\mathbf{R}^{2}$ & AIC & $\mathbf{n}$ \\
\hline $\mathbf{F I}$ & -0.103 & 28.719 & -0.097 & 28.677 & 0.163 & 26.512 & -0.099 & 28.691 & 0.776 & 19.959 & 0.079 & 22.785 & -0.339 \\
\hline $\mathbf{F 2}$ & 0.878 & 17.559 & 0.872 & 18.001 & 0.635 & 26.360 & 0.874 & 17.854 & 0.999 & -14.027 & 0.994 & -4.477 & 1.835 \\
\hline $\mathbf{F 3}$ & 0.842 & 20.841 & 0.834 & 21.225 & 0.598 & 28.295 & 0.837 & 21.099 & 0.984 & 6.446 & 0.984 & 4.316 & 2.026 \\
\hline F4 & 0.885 & 35.032 & 0.878 & 35.496 & 0.718 & 42.220 & 0.881 & 35.312 & 0.960 & 30.622 & 0.896 & 36.243 & 1.880 \\
\hline F5 & 0.918 & 32.792 & 0.899 & 34.439 & 0.696 & 43.249 & 0.905 & 33.910 & 0.996 & 13.014 & 0.975 & 25.325 & 1.500 \\
\hline F6 & 0.920 & 30.480 & 0.905 & 31.845 & 0.703 & 40.968 & 0.910 & 31.398 & 0.997 & 7.061 & 0.968 & 25.072 & 1.446 \\
\hline F7 & 0.952 & 35.408 & 0.905 & 37.309 & 0.717 & 46.042 & 0.912 & $36.68 I$ & 1.000 & -1.225 & 0.963 & 31.931 & 1.378 \\
\hline F8 & 0.947 & 25.182 & 0.935 & 26.842 & 0.748 & 37.716 & 0.939 & 26.302 & 0.988 & 18.004 & 0.967 & 23.878 & 1.393 \\
\hline F9 & 0.849 & 34.254 & 0.833 & 35.075 & 0.651 & 41.754 & 0.839 & 34.808 & 0.983 & 19.272 & 0.973 & 21.111 & 1.421 \\
\hline FIO & 0.853 & 0.850 & 0.848 & 34.337 & 0.761 & 37.896 & 0.850 & 34.233 & 0.860 & 37.674 & 0.853 & 36.030 & 0.995 \\
\hline FII & 0.566 & 39.859 & 0.562 & 39.935 & 0.537 & 40.381 & 0.564 & 39.909 & 0.619 & 42.815 & 0.569 & 41.804 & 0.879 \\
\hline$F \mid 2$ & 0.652 & 39.694 & 0.650 & 39.739 & 0.637 & 40.033 & 0.651 & 39.722 & 0.696 & 42.612 & 0.669 & 41.439 & 0.788 \\
\hline$F 13$ & 0.913 & 43.533 & 0.897 & 44.916 & 0.824 & 49.189 & 0.905 & 44.292 & 0.913 & 47.574 & 0.914 & 45.487 & 0.960 \\
\hline FI4 & 0.575 & 54.707 & 0.617 & 53.858 & 0.693 & 52.099 & 0.606 & 54.099 & 0.686 & 56.283 & 0.694 & 54.081 & 0.465 \\
\hline FI5 & 0.681 & 55.319 & 0.686 & 55.189 & 0.691 & 55.081 & 0.669 & 55.176 & 0.702 & 58.775 & 0.708 & 56.619 & 0.709 \\
\hline F16 & 0.970 & 35.120 & 0.936 & 41.110 & 0.810 & 49.796 & 0.949 & 39.336 & 0.978 & 36.390 & 0.979 & 34.169 & 1.178 \\
\hline FI7 & 0.967 & 36.981 & 0.925 & 43.466 & 0.795 & 51.516 & 0.940 & 41.639 & 0.982 & 36.104 & 0.982 & 34.089 & 1.234 \\
\hline FI 8 & 0.953 & 38.221 & 0.922 & 42.308 & 0.803 & 49.748 & 0.934 & 40.988 & 0.961 & 40.767 & 0.961 & 38.878 & 1.157 \\
\hline FI9 & 0.957 & 40.156 & 0.904 & 46.586 & 0.768 & 53.684 & 0.923 & 44.854 & 0.986 & 34.982 & 0.986 & 33.231 & 1.340 \\
\hline F20 & 0.778 & 57.427 & 0.900 & 51.041 & 0.875 & 52.856 & 0.883 & 52.277 & 0.919 & 53.383 & 0.881 & 54.425 & 0.592 \\
\hline F2I & 0.962 & 48.358 & 0.852 & 59.165 & 0.781 & 62.273 & 0.893 & 56.541 & 0.998 & 27.639 & 0.976 & 46.451 & 1.221 \\
\hline F22 & 0.929 & 52.355 & 0.806 & 60.366 & 0.706 & 63.682 & 0.845 & 58.540 & 0.997 & 31.255 & 0.994 & 34.009 & $1.56 \mid$ \\
\hline F23 & 0.933 & 64.062 & 0.958 & 59.504 & 0.892 & 68.930 & 0.976 & 53.669 & 0.993 & 44.907 & 0.964 & 59.998 & 0.790 \\
\hline F24 & 0.991 & 39.048 & 0.967 & 52.554 & 0.859 & 67.169 & 0.984 & 45.381 & 0.997 & 30.981 & 0.993 & 38.893 & 0.945 \\
\hline
\end{tabular}

\section{Fourier Transform Infrared Studies}

FTIR study indicated that the drug maintained its integrity; mesalamine displayed all the major peaks inside the fingerprint region of $500-2000 \mathrm{~cm}^{-1}$.

\section{Discussion}

On average, an oral dosage form may remain in the stomach for $2 \mathrm{~h}$ and in the intestine for $4 \mathrm{~h}$, thus the average time for a formulation to arrive at the colon is $6 \mathrm{~h}^{39}$ The rapid and extensive absorption of mesalamine in the small intestine causes a minor local action on mucosa and substantial systemic side effects. ${ }^{9}$ Therefore, a delivery system was designed to retard drug release until $6 \mathrm{~h}$ and to liberate at least $70 \%$ drug by $12 \mathrm{~h}$. In the present study, the milled form of DCP was used during three stages, ie, Mix, GS-2, and F mix according to the literature. ${ }^{40}$ The weights of ingredients in a pharmaceutical formulation are relative to each other, ie, when weight of one is changed, at least weight of one other ingredient has to be changed to keep the final weight of the tablet constant. The change in the relative weights in formulation of the individual ingredients is usually compensated with that of the bulking agent to achieve a fixed weight of the formulation. In this study, though DCP was used as a bulking agent, when it was combined with Eudragit-S100, it was found to act as a modulator for release, in line with literature, according to which the DCP, despite acting as a diluent in direct compression, might also retard drug release, a potential of DCP that had not been well explored. ${ }^{16}$ Hence, the amount of DCP was not adjusted to make up for achieving a fixed weight of all formulations. Thus, the final weight of the tablet formulations depended upon the amount of DCP and Eudragit-S100 in the blend. Table 1 shows the different final weights of the tablets. Keeping the foregoing discussion in mind, another bulking agent should have to be added in formulations, but keeping the formulation with least numbers and quantity of ingredients was also an intention. The formulation F24 was the optimized tablet, its final weight was $575.2 \mathrm{mg}$. Unlike statistical approach such as design of experiment, the ANN is based on the learning of the patterns in the data, it is capable of capturing the effect of the change, parallel or unparallel in the ratios of the inputs on the final properties of the formulation. In this study, tablets' final weights were not entered as the properties so prediction of the optimized formulation was not affected by the different weights of the tablet formulations. Moreover DCP can be a source of $\mathrm{Ca}++$ and Heemskerk et $\mathrm{al}^{41}$ and Jing et $\mathrm{al}^{42}$ have separately shown that 
Table 4 Optimized Formulations Predicted by ANN

\begin{tabular}{|c|c|c|c|c|c|c|}
\hline \multicolumn{7}{|c|}{ Set of Optimized Compositions } \\
\hline Inputs & Set I & Set 2 & Set 3 & Set 4 & \multicolumn{2}{|l|}{ Set 5} \\
\hline Eudragit-SIO0 (mg) & 12 & 12 & 12 & 12 & \multicolumn{2}{|l|}{12} \\
\hline DCP-Internall (mg) & 30 & 35 & 30 & 25 & \multicolumn{2}{|l|}{35} \\
\hline DCP-Internal2 (mg) & 49 & 56 & 42 & 35 & \multicolumn{2}{|l|}{49} \\
\hline DCP-External (mg) & 42 & 42 & 42 & 35 & \multicolumn{2}{|l|}{42} \\
\hline PVP-Internal (mg) & 40 & 40 & 40 & 40 & \multicolumn{2}{|l|}{40} \\
\hline \multirow[t]{2}{*}{ Outputs } & \multirow[t]{2}{*}{ Desired Response } & \multicolumn{5}{|c|}{ Predicted values of sets of outputs } \\
\hline & & $\mathbf{I}$ & 2 & 3 & 4 & 5 \\
\hline Hardness $\left(\mathrm{kg} / \mathrm{cm}^{2}\right)$ & 7 & 2.644 & 2.731 & 3.243 & 3.105 & 3.331 \\
\hline Release 2 (\%) & 30 & 30.877 & 29.599 & 28.124 & 28.907 & 26.798 \\
\hline Release 3 (\%) & 35 & 23.866 & 24.015 & 23.026 & 23.572 & 23.199 \\
\hline Release 4 (\%) & 45 & 44.056 & 44.393 & 42.241 & 43.308 & 42.606 \\
\hline Release 5 (\%) & 50 & 47.738 & 48.191 & 48.056 & 48.910 & 48.493 \\
\hline Release 6 (\%) & 55 & 59.736 & 60.372 & 58.690 & 59.678 & 59.397 \\
\hline Release 7 (\%) & 65 & 64.276 & 65.961 & 63.020 & 61.709 & 64.908 \\
\hline Release 8 (\%) & 70 & 72.288 & 73.601 & 70.526 & 71.864 & 72.142 \\
\hline \multicolumn{2}{|l|}{ Sum of Abs. Error } & 27.321 & 28.005 & 28.507 & 29.031 & 29.204 \\
\hline
\end{tabular}

blood clotting is expedited when cytosol $\mathrm{Ca}^{++}$is increased. This increased cytosolic $\mathrm{Ca}^{++}$in $\mu \mathrm{M}$ range, even for minutes, can evoke platelet membrane blebbing and phosphatidylserine (PS) exposure leading to coagulation of bleeding scars.

Being sans statistical-intensive approach, the predictivity and suitability of the ANN model is assessed through RMSE; RMSE $<1$ indicates appropriateness of data training and adequacy of model for a reliable prediction. ${ }^{18}$ ANN predicted the relative importance of each of the ingredients shown in Figure 5 for overall properties of formulation

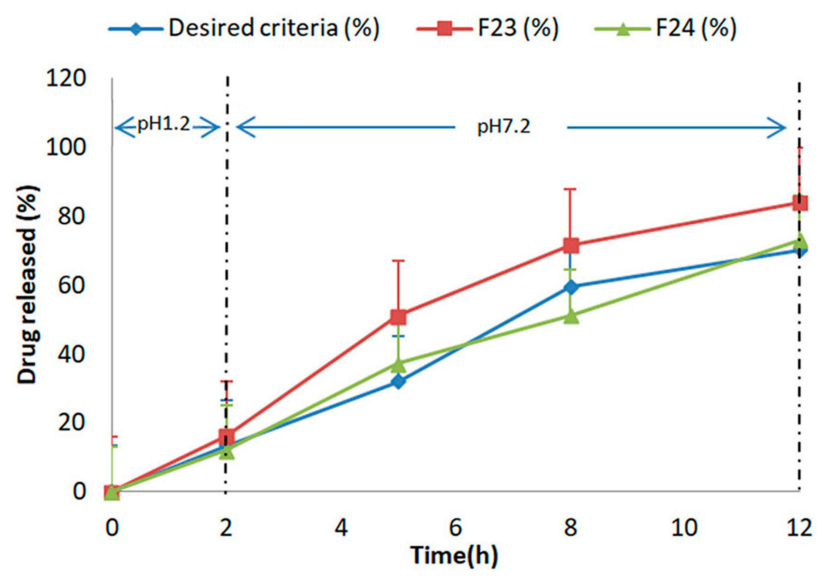

Figure 4 Comparative \% release studies of mesalamine from formulation F23-F24 with reference release data using $0.2 \mathrm{M} \mathrm{HCl}$ for $2 \mathrm{~h}$ at $\mathrm{pH} 1.2$ and $0.2 \mathrm{M}$ phosphate buffer at $\mathrm{pH} 7.2$ for further $10 \mathrm{~h}$. which were ranked as Eudragit-S100> DCP internal 1> used in pre-granulation stage DCP internal $2>$ used in intragranulation stage DCP external $>$ PVP internal used in extragranulation stage as explained earlier. Thus, the summary of combined effect of Eudragit-S100, DCP internal 1 (mixed during GS1), DCP internal 2 (mixed during GS2), DCPexternal and PVP-Internal only has been shown in Table 5.

DCP, being an insoluble filler, was mainly focused on because of its earlier reported release retardant property, ${ }^{43}$ good flowability, and its action by reducing Fickian diffusion with increasing erosion rate of matrix for sustained release drug delivery from a simple uncoated matrix tablet. ${ }^{43,44}$ The desired hardness of less than $8 \mathrm{~kg} / \mathrm{cm}^{2}$ was obtained by varying amounts of Eudragit-S100 and DCP-internal 1 (Figure 6A), showing that the concentrations of both excipients played a critical role in hardness parameter. The maximum amount of drug was released with the highest concentration of DCPinternal 1 . The desired $30 \%$ release was obtained at a point with the minimum amount of Eudragit- and maximum amount of DCP-internal 1. This showed the least effect of Eudragit- on release at $2 \mathrm{~h}$ (Figure 6B).

The desired 35 and $45 \%$ release at $3 \mathrm{~h}$ and release at $4 \mathrm{~h}$ were not obtained with this amount of excipients. The predicted pattern gives the maximum amount of drug released 25 and $40 \%$ at 3 and $4 \mathrm{~h}$ at the highest concentration of Eudragitand least effect of DCP-Internal 1. This showed that Eudragit- 


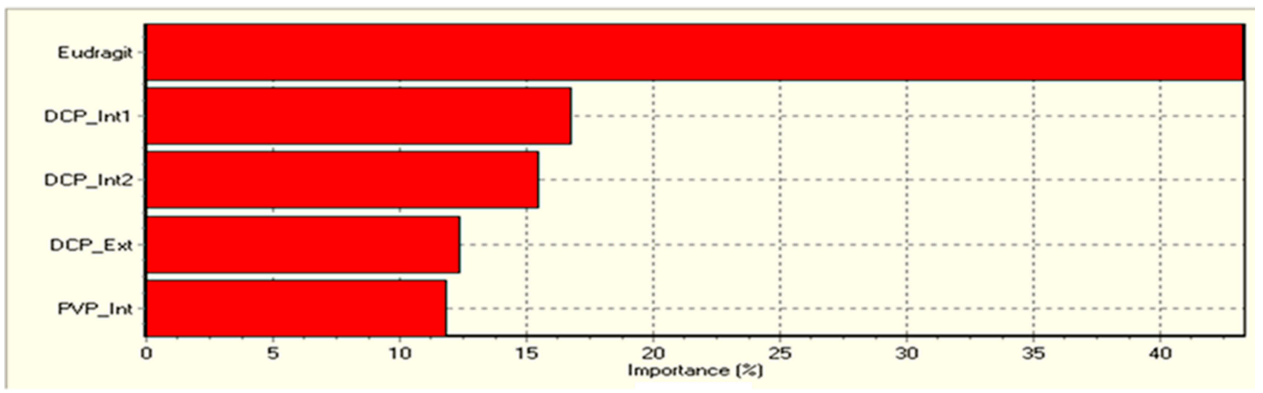

Figure 5 Relative significance of ingredients for the mesalamine colonic system for overall properties of formulation which were ranked as Eudragit-SI00> DCP internal I used in pre-granulation or Mix stage> DCP internal 2 used in intra-granulation stage or GS-2> DCP external used in F-Mix stage > PVP internal used in extra-granulation stage.

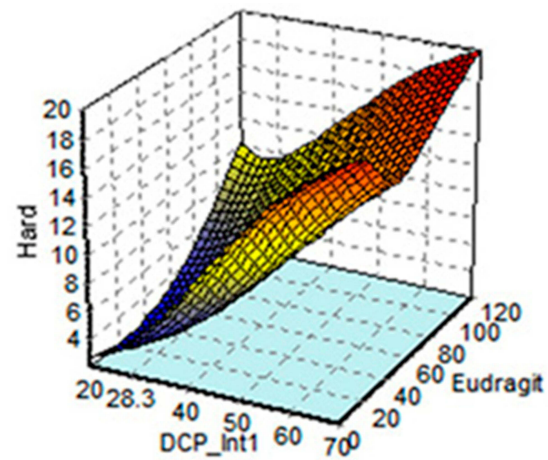

A: Hardness

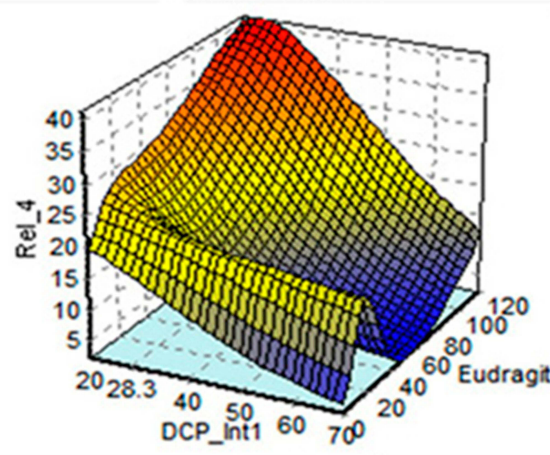

D: Release $4^{\text {th }} \mathrm{h}$

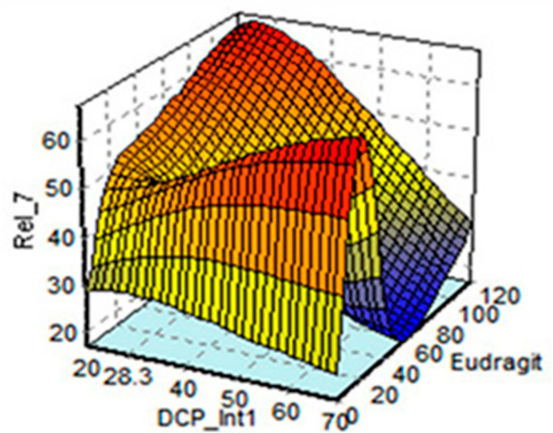

G: Release $7^{\text {th }} \mathrm{h}$

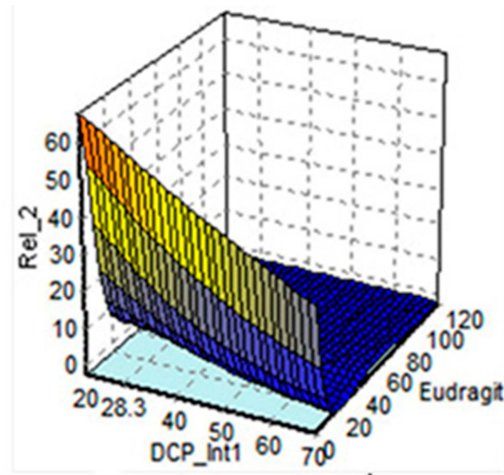

B: Release $2^{\text {nd }} h$

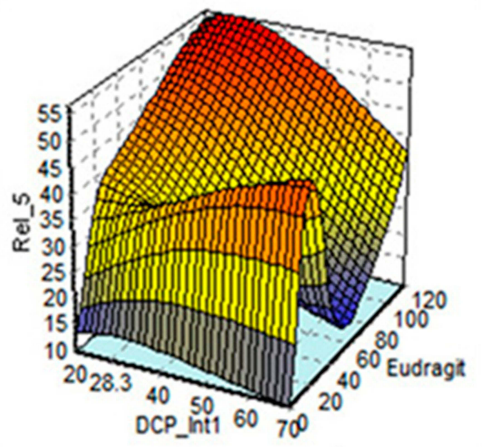

E: Release $5^{\text {th }} \mathrm{h}$

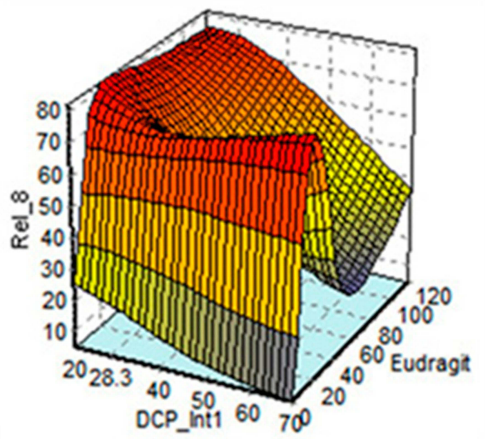

$\mathrm{H}:$ Release $8^{\text {th }} \mathrm{h}$

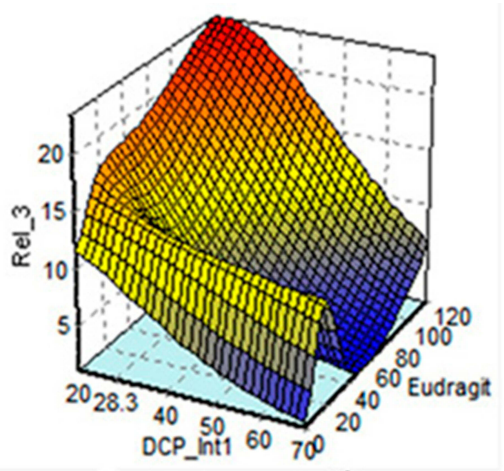

C: Release $3^{\text {rd }} \mathrm{h}$

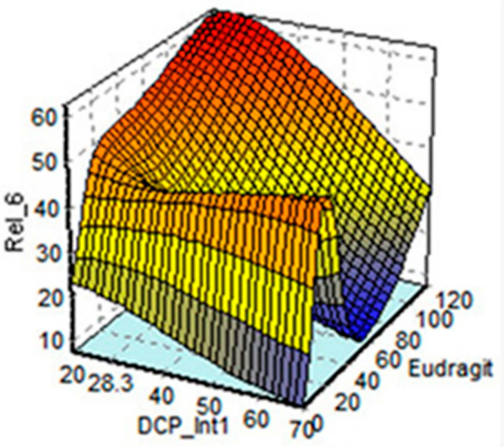

F: Release $6^{\text {th }} \mathrm{h}$

Figure 6 Response surface plots of: (A) hardness: showing that desired hardness of less than $8 \mathrm{~kg} / \mathrm{cm}^{2}$ was obtained by varying amount of Eudragit-SI00 and DCP-Internall. (B) Release at $2 \mathrm{~h}$ : showing the least effect of Eudragit-S 100 on release at $2 \mathrm{~h}$ (C) and (D) release at $3 \mathrm{~h}$ and $4 \mathrm{~h}$ : showing that Eudragit-SI00 and DCP Internal I did not impart a significant effect on drug release at $3 \mathrm{~h}$ and $4 \mathrm{~h}$. (E) and (F) release at $5 \mathrm{~h}$ and $6 \mathrm{~h}$ : showing the least effect of DCP-Internal I on drug release at $5 \mathrm{~h}$ and $6 \mathrm{~h}$. (G, $\mathbf{H})$ Release at $7 \mathrm{~h}$ and $8 \mathrm{~h}$ : showing the maximum amount of drug was released with the higher amount of Eudragit-SI00 and minimum amount of DCP-Internal I at $7 \mathrm{~h}$ and $8 \mathrm{~h}$. 
Table 5 Summary of Effect of Ingredients on Parameters

\begin{tabular}{|c|c|c|c|c|c|}
\hline \multirow[t]{2}{*}{ Parameters } & \multicolumn{5}{|l|}{ Ingredients } \\
\hline & Eudragit-S 100 & DCP-Internal I & DCP-Internal2 & DCP-External & PVP-Internal \\
\hline Hardness & $\uparrow^{a}$ & $\uparrow$ & $\uparrow$ & $\downarrow^{b}$ & $\downarrow$ \\
\hline Release 2(h) & $\downarrow$ & $\uparrow$ & $\uparrow$ & $\uparrow$ & $\uparrow$ \\
\hline Release 3(h) & $\leftrightarrow^{c}$ & $\leftrightarrow$ & $\leftrightarrow$ & $\leftrightarrow$ & $\leftrightarrow$ \\
\hline Release 4(h) & $\leftrightarrow$ & $\leftrightarrow$ & $\leftrightarrow$ & $\uparrow$ & $\uparrow$ \\
\hline Release 5(h) & $\uparrow$ & $\downarrow$ & $\downarrow$ & $\uparrow$ & $\uparrow$ \\
\hline Release 6(h) & $\uparrow$ & $\downarrow$ & $\downarrow$ & $\uparrow$ & $\uparrow$ \\
\hline Release 7(h) & $\uparrow$ & $\downarrow$ & $\uparrow$ & $\uparrow$ & $\uparrow$ \\
\hline Release 8(h) & $\uparrow$ & $\downarrow$ & $\uparrow$ & $\uparrow$ & $\uparrow$ \\
\hline
\end{tabular}

Notes: ${ }^{a}$ Increase; ${ }^{b}$ decrease; ${ }^{c}$ no effect.

Table 6 Dissolution Profile of Commercially Available Mesalamine, F-23 and F-24

\begin{tabular}{|l|l|l|l|}
\hline $\begin{array}{l}\text { Time } \\
\text { (h) }\end{array}$ & $\begin{array}{l}\text { Commercially Available } \\
\text { Mesalamine (\%) }\end{array}$ & F 23 (\%) & F 24 (\%) \\
\hline 2 & 1.05 & 16.14 & 12.09 \\
3 & 0.68 & 22.16 & 16.17 \\
4 & 0.56 & 37.20 & 27.11 \\
5 & 84.20 & 51.11 & 37.17 \\
6 & 100.41 & 58.10 & 41.12 \\
7 & - & 64.12 & 47.12 \\
8 & - & 71.66 & 51.14 \\
10 & - & 81.83 & 63.08 \\
12 & - & 83.91 & 72.96 \\
\hline
\end{tabular}

S100 and DCP-Internal 1 have not imparted a significant effect on drug release at 3 and $4 \mathrm{~h}$ (Figure $6 \mathrm{C}$ and D).

The maximum amount of drug was released with the highest concentration of Eudragit- and minimum concentration of DCP-Internal 1 for release at 5 and $6 \mathrm{~h}$. The desired 50 and $55 \%$ release at 5 and $6 \mathrm{~h}$ respectively were obtained at the minimum level of DCP-Internal 1 and maximum level of Eudragit-. This shows the least effect of DCP-Internal 1 on Release $5 \& 6$ (Figure 6E and F).

The desired 65 and $70 \%$ drug release at 7 and $8 \mathrm{~h}$, respectively were obtained at highest concentration of Eudragit-. The maximum amount of drug was released with the higher amount of Eudragit- and minimum amount of DCP-Internal 1 (Figure 6G and H).

The predicted graphical representation of hardness and $2-8 \mathrm{~h}$ release study from $\mathrm{ANN},{ }^{34}$ showed that Eudragit-S100 has a critical effect on physicochemical factor, ie, hardness and in-vitro drug dissolution release profile at 2, 3, 4, 5, 6, 7, and $8 \mathrm{~h}$. The effect of DCP-Internal 1 showed a more pronounced effect on hardness of tablets rather than on the drug release, as summarized in Table 5.

Dissolution profile of commercially available mesalamine have shown $100 \%$ release until 6 h, instead, F23 and F24 (Table 6) have shown a marked difference among their respective release data at different time intervals and retarded the drug release until $12 \mathrm{~h}$. Pulsatile release pattern of commercially available mesalamine validates our delayed release formulation which showed $70 \%$ release until $12 \mathrm{~h}^{45}$

Weibull model is more useful in comparing the release profiles of matrix type drug delivery that has been described for different types of dissolution processes. ${ }^{30}$

Weibull model, $\log [-\ln (1-\mathrm{m})]=\mathrm{b} \log [\mathrm{t}-\mathrm{Ti}]-\log \mathrm{a}$, fitted the data of optimized formulation. This model explains the dissolution process of matrix type of drug delivery in the following equation 9 :

$$
\mathrm{M}=\mathrm{M}_{0}\left[1-\mathrm{e}^{\frac{-\left(\mathrm{t}-\mathrm{T}^{\mathrm{b}}\right.}{\mathrm{a}}}\right]
$$

where $\mathrm{M}$ is the amount of drug dissolved as a function of time t. $\mathrm{M}_{0}$ is total amount of drug being released, and $\mathrm{T}$ is the lag time. The equation parameter " $a$ " is a scale parameter that describes the time dependence and "b" determines the progression of shape of the dissolution curve. If $\mathrm{b}=1$, the rise in curve corresponds to an exponential profile with a constant $\mathrm{k}=1 / \mathrm{a}$ and the previous equation could be rewritten as:

$$
\mathrm{M}=\mathrm{M}_{0}\left[1-\mathrm{e}^{-\mathrm{k}(\mathrm{t}-\mathrm{T}}\right]
$$

The $\mathrm{b}$ value higher than 1 yields a sigmoidal curve with a turning point, while $b$ lower than 1 produces a steeper increase. Using the inverse function of the previous equation, $\mathrm{T}_{50 \%}$ and $\mathrm{T}_{90 \%}$ is calculated. The $\mathrm{b}$ value of the formulation 
<smiles>COC(=O)c1cc(N=N)ccc1O</smiles>

\section{A: Mesalamine Chemical Structure}

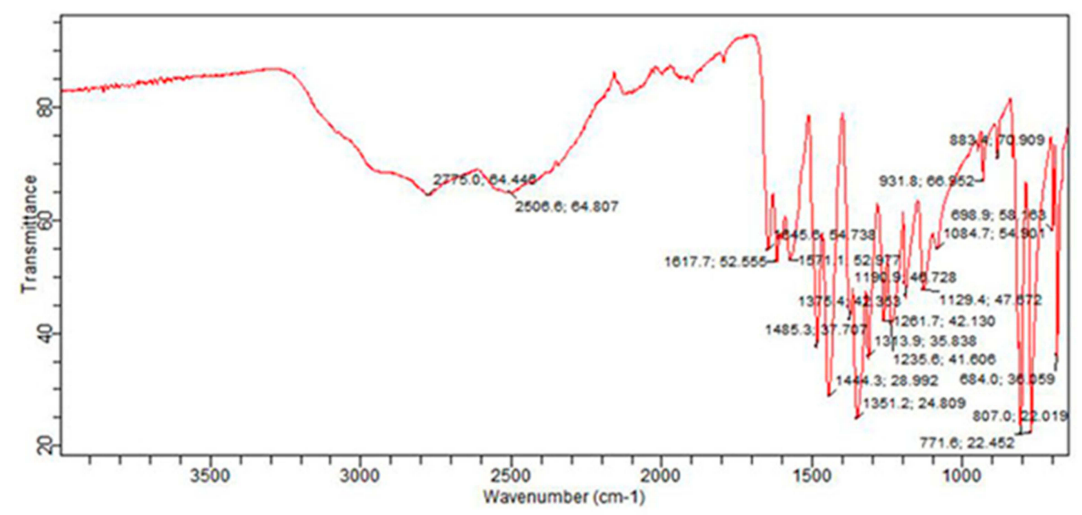

B: Mesalamine FTIR

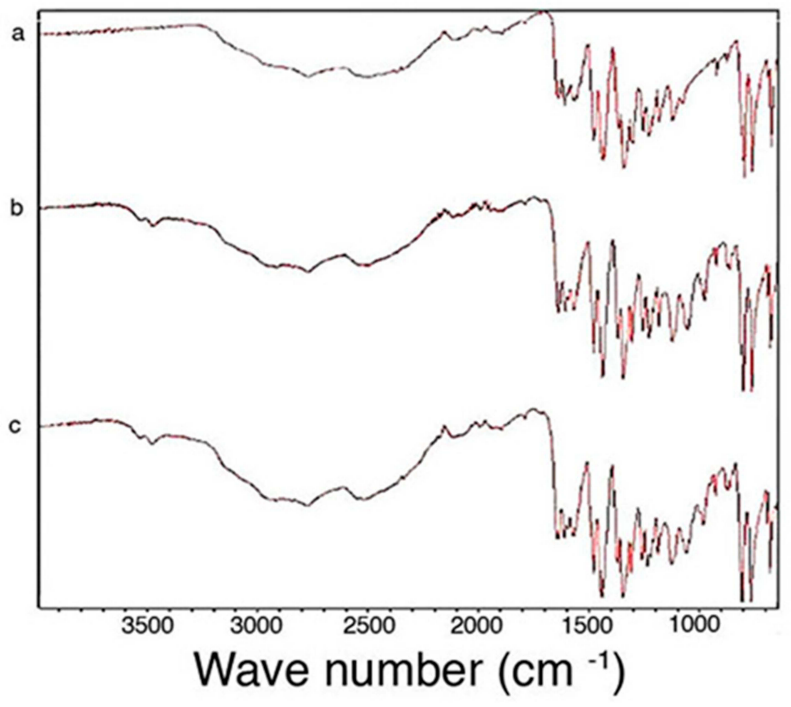

C: FTIR spectra of (a): Mesalamine: (b): Granules: (c): Tablet

Figure $7 \mathrm{FTIR}$ spectra. (A) Mesalamine chemical structure. (B) Mesalamine FTIR peaks showing the $-\mathrm{NH}_{2}$ functional group bending peak and $\mathrm{C}=\mathrm{O}$ functional group stretching at $1615-1700 \mathrm{~cm}^{-1}$, along with C-O stretch at $1215 \mathrm{~cm}^{-1}$. (C) FTIR spectra of (a) mesalamine; (b) mesalamine granules; (c) mesalamine tablet showing characteristic peaks of mesalamine functional groups in spectra of mesalamine, mesalamine matrix tablets, and granules with indication of no excipient-drug incompatibility.

F24 was found to be 1.3 , greater than 1 generating a sigmoidal curve with a minor lag time.

The characteristic peaks of mesalamine functional groups were found in both spectra of mesalamine matrix tablets and granules. The $-\mathrm{NH}_{2}$ functional group bending peak and $\mathrm{C}=\mathrm{O}$ functional group stretching was observed at 1615-1700 $\mathrm{cm}^{-1}$, along with $\mathrm{C}-\mathrm{O}$ stretch at $1215 \mathrm{~cm}^{-1}$, indicating that mesalamine was stable during granulation and tableting procedure and there was no indication of any excipient-drug incompatibility nor denaturation of drug during manufacturing procedure. The chemical structure of mesalamine and its chemical peaks have been shown (Figure 7A and B) respectively. The FTIR spectra of mesalamine, mesalamine granules and tablets are shown (Figure 7C $(\mathrm{a}-\mathrm{c})$ ). 


\section{Conclusion}

The combination of Eudragit-S100 and dicalcium phosphate, was used to develop the delayed release matrix tablet with the aid of artificial neural network (ANN) which helped to control the release of the mesalamine. The optimized uncoated matrix tablet surpass the stomach and intestinal conditions without any major drug release for $2 \mathrm{~h}$ and $6 \mathrm{~h}$ respectively and the drug maintained its integrity until $12 \mathrm{~h}$ up to $70 \%$. FTIR spectra showed that mesalamine did not show any interaction with the previously mentioned novel combination. DCP is used as a critical excipient in terms of multiple purposes, ie, as bulking agent and mainly as release retardant which has not been used in previous colon-specific drug delivery systems. Formulations F-23 and F-24 are the candidates for in-vivo evaluation in comparison to any of the products available on the market. Comparative dissolution study of the commercially available mesalamine and our newly developed matrix tablet showed a sustained drug release until $12 \mathrm{~h}$ of the latter. This sustainability of mesalamine along with increased residence time in the colon with comfortable dosage form signify its novelty as compared to the enteric coated products. The role of $\mathrm{Ca}^{++}$provided by DCP needs further exploration in reducing blood clotting time of bleeding scars in the colon in-vivo.

\section{Acknowledgment}

The authors are thankful to the management of Lahore Medical and Dental College and Department of Pharmaceutics, Faculty of Pharmacy, Bahauddin Zakariya University, Multan for their kind support in completion of this project.

\section{Disclosure}

The authors report no conflicts of interest in this work.

\section{References}

1. Cuffari C, Pierce D, Korczowski B, et al. Randomized clinical trial: pharmacokinetics and safety of multimatrix mesalamine for treatment of pediatric ulcerative colitis. Drug Des Devel Ther. 2016;10:593. doi:10.2147/DDDT.S95316

2. Perrotta C, Pellegrino P, Moroni E, et al. Five-aminosalicylic acid: an update for the reappraisal of an old drug. Gastroenterol Res Pract. 2015;2015:9. doi:10.1155/2015/456895

3. Pierce D, Corcoran M, Martin P, et al. Effect of $M M X^{\circledR}$ mesalamine coadministration on the pharmacokinetics of amoxicillin, ciprofloxacin $\mathrm{xr}$, metronidazole, and sulfamethoxazole: results from four randomized clinical trials. Drug Des Devel Ther. 2014;8:529. doi:10.2147/DDDT. S55373
4. Khan AM, Bashir S, Hanif M, Abbas N, Ahsan M. Colon specific formulation of mesalamine: preparation and in vitro evaluation. Lat Am J Pharm. 2016;35(6):1391-1398.

5. Jin L, Ding Y-C, Zhang Y, Xu X-Q, Cao Q. A novel pH-enzymedependent mesalamine colon-specific delivery system. Drug Des Devel Ther. 2016;10:2021.

6. Jakate A, McNamee B, Burkindine D. Bioavailability and swallowability of an age-appropriate, delayed-release mesalamine formulation in healthy volunteers. Clin Pharmacol. 2019;11:93.

7. Trivedi DH, Puranik KP. Colon targeted delivery system (CODESTM): propitious approaches in targeting colon. World J Pharm Pharm Sci. 2017;6(4):768-789.

8. Elbary AA, Aboelwafa AA, Al Sharabi IM. Once daily, high-dose mesalazine controlled-release tablet for colonic delivery: optimization of formulation variables using box-behnken design. AAPS PharmSciTech. 2011;12(4):1454-1464. doi:10.1208/s12249-011-9708-9

9. Deck D, Winston L, Katzung B, Masters S, Trevor A. Basic \& Clinical Pharmacology. McGraw-Hill Medical; 2012.

10. Goyanes A, Hatton GB, Merchant HA, Basit AW. Gastrointestinal release behaviour of modified-release drug products: dynamic dissolution testing of mesalazine formulations. Int J Pharm. 2015;484 (1-2):103-108. doi:10.1016/j.ijpharm.2015.02.051

11. Feagan BG, Chande N, MacDonald JK. Are there any differences in the efficacy and safety of different formulations of oral 5-ASA used for induction and maintenance of remission in ulcerative colitis? Evidence from cochrane reviews. Inflamm Bowel Dis. 2013;19 (9):2031-2040. doi:10.1097/MIB.0b013e3182920108

12. Nagaraju R, Swapna Y, Babu RH, Kaza R. Design and evaluation of delayed and extended release tablets of mesalamine. J Pharm Technol. 2010;2(1):103-110.

13. Edmunds MW. Introduction to Clinical Pharmacology-e-Book. Elsevier Health Sciences; 2015.

14. Bourgeois S, Harvey R, Fattal E. Polymer colon drug delivery systems and their application to peptides, proteins, and nucleic acids. $\mathrm{Am}$ J Adv Drug Deliv. 2005;3(3):171-204. doi:10.2165/00137696200503030-00003

15. Herrlich S, Spieth S, Messner S, Zengerle R. Osmotic micropumps for drug delivery. Adv Drug Deliv Rev. 2012;64(14):1617-1627. doi:10.1016/j.addr.2012.02.003

16. Rowe RC, Sheskey PJ, Quinn M. Handbook of pharmaceutical excipients-7th edition. Pharm Dev Technol. 2013;18:544.

17. Aulton ME, Taylor KM. Aulton's Pharmaceutics e-Book: The Design and Manufacture of Medicines. Elsevier Health Sciences; 2017.

18. Bukhari NI, Julianto T, Valente Pereira RE, et al. Computer-aided prediction of cefotaxime sodium stability in aqueous solution at different $\mathrm{pH}$ from sparse data. Lat Am J Pharm. 2018;37(3):571-578.

19. Patel Jayvadan K, Patel Nirav V, Shah Shreeraj H. Formulation and in-vitro evaluation of mesalamine matrix tablets using chitosan for colonic drug delivery. J Pharm Res. 2009;2(7):1319-1323.

20. Chiesi P, Ventura P, Mezzadri R, Brambilla G, Acerbi D. Pharmaceutical Compositions Containing an Effervescent AcidBase Couple. Google Patents; 2004.

21. Kawakami Y, Sato N, Hoshino M, Kouyama T, Shiiki Z. Controlled Release Formulations Using Intelligent Polymers. Google Patents; 2005.

22. Harish G, Bhargavi C, Riyajune A, et al. Effect of different disintegrants on ciprofloxacin conventional tablets. IJRPB. 2013;1(3):281.

23. Ratnaparkhi MP, Mohanta G, Upadhyay L. Review on: fast dissolving tablet. J Pharm Res. 2015;2:5-12.

24. Pawar KP, Gautam C. Design, optimization and evaluation of mesalamine matrix tablet for colon drug delivery system. Int $J$ Pharm Investig. 2016;46(1):67-78. doi:10.1007/s40005-015-0214-z

25. United States Pharmacopeia 35 - National Formulary 30 (USP 35NF 30). Rockville: United States Pharmacopeial Convention; 2011. Available from: https://www.uspnf.com/purchase-usp-nf/usp-nfarchive. 
26. Bendas ER, Christensen JM, Ayres JW. Development and in vitro evaluation of mesalamine delayed release pellets and tableted reservoir-type pellets. Drug Dev Ind Pharm. 2010;36(4):393-404. doi: $10.3109 / 03639040903213717$

27. Stolk L, Rietbroek R, Wiltink E, Tukker J. Dissolution profiles of mesalazine formulations in vitro. Pharm Weekbl Sci. 1990;12 (5):200-204. doi:10.1007/BF01980047

28. Jain S, Yadav S, Patil U. Preparation and evaluation of sustained release matrix tablet of furosemide using natural polymers. Res J Pharm Technol. 2008;1(4):374-376.

29. Dash S, Murthy PN, Nath L, Chowdhury P. Kinetic modeling on drug release from controlled drug delivery systems. Acta Pol Pharm. 2010;67(3):217-223.

30. Lokhandwala H, Deshpande A, Deshpande S. Kinetic modeling and dissolution profiles comparison: an overview. Int J Pharm Bio Sci. 2013;4(1):728-773.

31. Zhang Y, Huo M, Zhou J, et al. Ddsolver: an add-in program for modeling and comparison of drug dissolution profiles. AAPS J. 2010;12:263-271. doi:10.1208/s12248-010-9185-1

32. Hussain A, Syed MA, Abbas N, et al. Development of ann optimized mucoadhesive buccal tablet containing flurbiprofen and lidocaine for dental pain. Acta Pharm. 2016;66(2):245-256. doi:10.1515/acph2016-0020

33. Manda A, Walker RB, Khamanga SM. An artificial neural network approach to predict the effects of formulation and process variables on prednisone release from a multipartite system. Pharmaceutics. 2019;11(3):109. doi:10.3390/pharmaceutics11030109

34. Ibric S, Jovanovic M, Djuric Z, et al. Artificial neural networks in the modeling and optimization of aspirin extended release tablets with Eudragit- 1100 as matrix substance. AAPS PharmSciTech. 2003;4 (1):62-70. doi:10.1208/pt040109

35. Rehman K, Amin MC, Muda S. Influence of beta-cyclodextrin and chitosan in the formulation of a colon-specific drug delivery system. Drug Res. 2013;63:657-662. doi:10.1055/s-0033-1349129
36. Elzein T, Nasser-Eddine M, Delaite C, Bistac S, Dumas P. FTIR study of polycaprolactone chain organization at interfaces. J Colloid Interface Sci. 2004;273(2):381-387. doi:10.1016/j.jcis.2004.02.001

37. Mehta R, Chawla A, Sharma P, Pawar P. Formulation and in vitro evaluation of Eudragit- s-100 coated naproxen matrix tablets for colon-targeted drug delivery system. JAPTR. 2013;4(1):31.

38. Chen S, Zhu J, Cheng J. Preparation and in vitro evaluation of a novel combined multiparticulate delayed-onset sustained-release formulation of diltiazem hydrochloride. Pharmazie. 2007;62 (12):907-913.

39. Tugcu-Demiroz F, Acarturk F, Takka S, Konus-Boyunaga O. In-vitro and in-vivo evaluation of mesalazine-guar gum matrix tablets for colonic drug delivery. $J$ Drug Target. 2004;12(2):105-112. doi:10.1080/10611860410001693751

40. Lachman L, Lieberman HA, Kanig JL. The Theory and Practice of Industrial Pharmacy. Lea \& Febiger Philadelphia; 2010.

41. Heemskerk JW, Bevers EM, Lindhout T. Platelet activation and blood coagulation. Thromb Haemost. 2002;88(08):186-193. doi:10.1055/ s-0037-1613209

42. Jing J, Sun Y. An $\alpha \mathrm{IIb} \beta 3$-and phosphatidylserine (PS)-binding recombinant fusion protein promotes ps-dependent anticoagulation and integrin-dependent antithrombosis. J Biol Chem. 2019;294 (17):6670-6684. doi:10.1074/jbc.RA118.006044

43. Bharate SS, Bharate SB, Bajaj AN. Interactions and incompatibilities of pharmaceutical excipients with active pharmaceutical ingredients: a comprehensive review. J Excip Food Chem. 2016;1(3):1131.

44. Jimini M, Kothari HA. Sustained release matrix type drug delivery system: a review. J Drug Deliv Ther. 2012;2(6).

45. Schellekens RC, Stuurman FE, van der Weert FH, Kosterink JG, Frijlink HW. A novel dissolution method relevant to intestinal release behaviour and its application in the evaluation of modified release mesalazine products. Eur J Pharm Sci. 2007;30(1):15-20. doi:10.1016/j.ejps.2006.09.004

\section{Publish your work in this journal}

Drug Design, Development and Therapy is an international, peerreviewed open-access journal that spans the spectrum of drug design and development through to clinical applications. Clinical outcomes, patient safety, and programs for the development and effective, safe, and sustained use of medicines are a feature of the journal, which has also been accepted for indexing on PubMed Central. The manuscript management system is completely online and includes a very quick and fair peer-review system, which is all easy to use. Visit http://www. dovepress.com/testimonials.php to read real quotes from published authors. 